\title{
A CRISE SOCIAL NO BRASIL: BREVE REFLEXÃO E APONTAMENTOS
}

\section{Gabrielle Diniz dos SANTOS $^{1}$; Alynete Andriola PEREIRA ${ }^{2}$}

\footnotetext{
${ }^{1}$ Bacharel em Ecologia, UFPB/Campus IV; Especialista em Planejamento Urbano e Gestão de Cidades, UNIPE; Mestre em Desenvolvimento e Meio Ambiente - PRODEMA/UFPB. E-mail: gabrielledsantos90@ gmail.com

${ }^{2}$ Bacharel em Relações Públicas, UFPB. E-mail: alyneteandriola@hotmail.com
}

Resumo: As políticas sociais se tornaram essenciais para a garantia de direitos de uma forma mais justa para a sociedade para um todo, seja ela periférica, ou sejam elas de classes sociais com poder aquisitivo maior, sendo a primeira de maior importância por sofrer exclusões sociais. Isso decorre do histórico brasileiro de injustiças sociais, bem como de sua divisão de classes desde seu processo de colonização exploratória, em sua maioria, decorrente das colônias portuguesas. Sendo assim, este trabalho tem como objetivo discutir as práticas das políticas públicas sociais, bem como sua importância para a sociedade e como estas têm evoluído. Para a obtenção dos dados necessários para a realização do trabalho foram realizadas pesquisas bibliográficas nas plataformas de busca do Google Acadêmico e em livros relacionados ao tema. Desta forma, é possível discorrer aqui que no decorrer dos anos pós colônia, o país foi se desenvolvendo e seu crescimento econômico garantiu além de melhoria na qualidade de vida dos brasileiros, a expansão das áreas periféricas fruto do tipo de crescimento de trabalho utilizado nas indústrias e na construção civil, somado ao baixo poder aquisitivo de parcela da população, que acabaram por se dar principalmente nas grandes cidades, estas marcadas pela expansão industrial e econômica. As cidades acabaram por se tornar espaços excludentes devido essa divisão social, a qual pode ser observada com maior veemência em cidades como São Paulo e Rio de Janeiro ainda nos dias atuais. Desta forma, é possível concluir que atualmente é necessária uma reforma política, onde sejam garantidos os direitos dos cidadãos de forma mais igualitária e assim, atenuar as diferenças sociais que tanto marcam nossa sociedade.

Palavras-chave: Políticas Públicas; Desenvolvimento Econômico; Divisão Social. 